\title{
Guest Editors' Foreword: Digital Humanities and/in Film Archives
}

DIMITRIOS LATSIS AND GRAZIA INGRAVALLE

The continuous redefinition of the role and purview of archivists and curators of moving image media has been driven, in no small measure, by the development of digital tools and networks. To better understand this shift and start mapping its current impact on archives and film preservation, this special issue of The Moving Image assembles perspectives from leading curators, archivists, academics, and digital humanists who have developed innovative platforms to disseminate the work done in moving image archival collections. They provide new tools and resources for both research and pedagogy, share best practices, discuss opportunities for collaboration, and address challenges from leading digital humanities (DH) projects in the audiovisual archival field.

Most of these projects are still in progress, so the reader will find that this collection of feature articles and Forum pieces signals the current developing status-or “iterative" nature, to quote Charles Tepperman-of the digital humanities. The contributions compellingly reflect the state of the field, while still leaving open critical questions for future discussion. One such question is certainly whether DH methodologies and tools advance new epistemologies and practices for research in film and media studies and in archival moving image collections. While our contributors reject the idea that by incorporating (partially) automated tasks, DH methodologies lend increased scientific credibility to media analyses and histories, they all highlight the heuristic value of its applications. As the articles in this special issue emphasize, many of the tasks involved in DH projects (creating a database, segmenting a film sequence, annotating, selecting variables, etc.) in fact force us to interrogate established vocabularies, prompting us 
once more to (re)define, for instance, "race film," a film "shot," or an "archival record." The digital humanities, as these examples show, encourage interinstitutional and interdisciplinary collaborations among scholars and archivists, inviting them to open up the results of their work to awareness, criticism, and debate.

Particular focus is placed on outreach initiatives that give access and visibility to nonfiction, amateur, and nontheatrical film: programming, platforms for user-contributed content, crowdsourcing, and original ways of annotating, sharing, and cross-referencing time-based media. We also address pedagogy that utilizes primary sources, facilitates (under)graduate research, and encourages broader stakeholders, such as K-12 instruction and local and community-based organizations.

Shane 0'Sullivan approaches these goals by exploring institutional projects that in the last fifteen years have granted access to British audiovisual archival materials for education. O'Sullivan particularly concentrates on the pioneering work of current British Film Institute (BFI) head of education Paul Gerhardt and the collaboration between the $\mathrm{BFI}$ and Kingston University on a pedagogical project teaching students to reuse moving image archive material in video essays.

Philipp Dominik Keidl expands a thorough consideration of the exhibition strategies of the Australian Centre for the Moving Image in Melbourne into a broader consideration of what media archaeological thinking and practices can mean outside the purview of academia, specifically as enabled by digital technologies and environments. An expanded and crucially public iteration of media archeology can stand as an equal partner and generator of discourse that leads to more conceptual contributions to film and media history.

Liliana Melgar Estrada, Eva Hielscher, Marijn Koolen, Christian Gosvig Olesen, Julia Noordegraaf, and Jaap Blom collaboratively survey different video annotation and editing tools widely used in media studies and production. The authors examine two kinds of video software, ELAN and NVivo, to analyze a sequence from People on Sunday (Robert Siodmak et al., 1930). They assess the advantages and drawbacks of each, along with the larger implications for moving image scholars, professionals, and archivists.

What would a digital humanities approach to film colors look like? In answering this question, Barbara Flueckiger reflects on the ERC Advanced Grant FilmColors project at the University of Zurich, an extension of one of the best-known DH projects to deal with film history, the Timeline of Historical Film Colors. With computer-assisted tools, such as video annotation and a database of color patterns from a wide array of films, FilmColors aims to merge quantitative and qualitative approaches to demonstrate what 
a highly technical methodology can make possible for the study of style and aesthetics, while also facilitating film archives' restoration workflows.

With “(Micro)film Studies,” María Antonia Vélez-Serna challenges archivists and historians to reconsider their definitions of preservation-worthy materials while tackling one of the most significant providers of paratexts for film and media histories: microfilm. She argues that widespread, systematic digitization (as evidenced in projects like the British Newspaper Archive and the Media History Digital Library) has revolutionized our methodologies and behavior as historians. These resources, though, bring about their own medium-specific challenges.

We move, then, to the University of California, Los Angeles-based DH project Early African American Film. Marika Cifor, Hanna Girma, William Lam, Shanya Norman, Miriam Posner, Karla Contreras, and Aya Grace Yoshioka discuss the methodological, historical, and epistemological questions they faced in building a comprehensive database of the African American race film industry between 1905 and 1930.

Charles Tepperman introduces readers to the newly launched Amateur Movie Database (AMDB), a digital resource that aims to advance knowledge about the history of amateur cinema. Using carefully researched metadata, visual and historical materials from a range of online and archival sources, and specially commissioned essays, AMDB is an excellent example of a $\mathrm{DH}$ project that can help catalyze preservation and recovery efforts for the enormously important category of nontheatrical cinema. The questions Tepperman poses (Whom should these projects, researchers, and archives address? How should they be organized and presented? What are the most effective digital tools and interfaces for our users?) are the same ones that film scholars and technologists are increasingly asking daily.

Paolo Simoni discusses the use of geodatabases and geolocation apps that help users interact with the growing collections of the Italian Amateur Film Archive in Bologna. These tools enable users to explore the changing landscape of the two Italian cities of Bologna and Reggio Emilia through the eyes of amateur filmmakers, advancing what Simoni defines as an urban "media stratigraphy."

The next article distances itself from traditional historians' concerns with archival films' textual dimension and investigates instead the archival traces of the activities of the makers, distributors, exhibitors, and audiences involved in the Media Arts Center Movement. Lindsay Kistler Mattock discusses Mapping the Independent Media Community, a DH project based at the University of lowa that maps the global entanglements between independent moving image artists, distributors, museums, governmental bodies, and local communities in the late 1970 s. 
Simona Monizza shares the perspective of a large-scale digitization and access project initiated by the EYE Filmmuseum in the Netherlands to preserve and make available short films, an often neglected but valuable mode of filmmaking. By discussing internal workflows and the process of dealing with exhibitors, and by providing an online platform for the project, Monizza demonstrates that film heritage dissemination does not compete but in fact can be synergetic with an investment in digital infrastructure and an engagement of the theatrical sector, along national and transnational lines.

In her report on the timely and highly innovative conference Transformations I: Cinema and Media Studies Research Meets Digital Humanities Tools (organized by New York University's Cinema Studies department on April 15-16, 2016), Marina Hassapopoulou considers the convergence of these two fields as evidenced by the work of the academics and technologists who participated in an atmosphere of exchange and collaboration. Out of the multiplicity of the participants' approaches, a consensus emerged that "the creation of tools, online research initiatives, and multimodal pedagogy should be considered as important humanities work" in its own right. The editors and contributors to the present issue of The Moving Image share this sentiment.

A review of a book that might well prove to be a pioneering starting point for the "institutionalization" of DH within the field of cinema studies rounds out our issue. The Arclight Guidebook to Media History and the Digital Humanities is arguably the first collection of essays specifically dedicated to the theory and practice of DH in moving image media. The book is part of the larger Project Arclight, which is a collaboration between Concordia University and the University of Wisconsin-Madison. As our reviewer, Bregt Lameris, surmises, the application behind it, the symposium in which this collection of essays originated, and the book provide very important new initiatives and possibilities for the use of digital tools in media historical research.

Finally, Jeremy Carr supplies an engaging review of Flicker Alley's recent Blu-ray release 3-D Rarities. We have distributors like Flicker Alley to thank for quietly restoring and making accessible films that might otherwise be forever confined to the archive or lost for the lay audience. Their new and back catalog releases (https://www.flickeralley .com/)-such as Early Women Filmmakers: An International Anthology, Masterworks of American Avant-Garde Experimental Film 1920-1970, and Chaplin's Mutual Comedies, to name a few-are equal parts entertaining and inspirational, setting a standard for quality and substance.

Our hope as editors is that this issue will act as a primer on some of the most significant recent developments in the fields of film history, archiving, and preservation. It should offer a tool kit for archivists and researchers looking for ideas and partners in 
implementing DH methodologies in their own work. We also hope that it will provoke a rethinking of the purposes, stakeholders, and ethical considerations of caring for and disseminating our audiovisual heritage in the twenty-first century.

Grazia Ingravalle holds a $\mathrm{PhD}$ in film studies from the University of St. Andrews and recently was awarded a Leverhulme Early Career Fellowship (2017-20) to work on her new research project about colonial archival films and contemporary archival exhibition practices. She is currently working on a book manuscript, titled Curating Film History: Film Museums and Archives in the Age of New Media, which is based on her dissertation.

Dimitrios Latsis is assistant professor of film studies at the School of Image Arts of Ryerson University in Toronto. He received his $\mathrm{PhD}$ in film studies from the University of Iowa and completed a postdoctoral fellowship in visual data curation at the Internet Archive, where he served as film curator. His work has been funded by the Smithsonian Institution, CLIR, and the Mellon Foundation, among others. He is currently coediting an anthology on documentaries about the visual arts produced in the 1950s and 1960s. 